\title{
Insulation workers in Belfast. 3. Mortality 1940-66
}

\author{
P. C. ELMES and MARION J. C. SIMPSON \\ Department of Therapeutics and Pharmacology, Queen's University, Belfast
}

\begin{abstract}
Elmes, P. C., and Simpson, Marion J. C. (1971). Brit. J. industr. Med., 28, 226-236. Insulation workers in Belfast. 3. Mortality 1940-66. One hundred and seventy men were identified as making up the total population of insulation workers in Belfast in 1940. This is an analysis of all the information about deaths that has emerged from tracing these men up to the end of 1966. Five remain untraced, and the mortality experience of the remainder is compared with that of other men in Northern Ireland over the period. There were 98 deaths when only 37 were expected. The number of deaths occurring exceeded those expected throughout the period 1940-66 and the increase was statistically significant during the period 1950-55 and onwards. There was an especially high mortality (compared with other Northern Ireland males) due to cancer of the lung, mesothelioma of the pleura and peritoneum, cancer of the gastrointestinal tract, and fibrotic lesions of the lungs. The ratio of observed over expected deaths was 2.6 for all causes, 3.9 for all cancers, and 17.6 for cancers of the lower respiratory tract and pleura. Those men finally classified as dying from lung cancer showed evidence of lung fibrosis whereas those classified as dying from mesothelioma did not. Comparisons within the group failed to show any relationship between age at first exposure or duration of exposure and the excessive mortality. There were too few non-smokers to show the significance of smoking.
\end{abstract}

The first two studies (Wallace and Langlands, 1971; Langlands, Wallace, and Simpson, 1971) were concerned with the health of men still employed as insulators; the third study is an attempt to evaluate the deaths which have occurred in this occupational group. For a complete picture of the occupational hazard it would also be necessary to find out the proportion of men who had to leave this occupation for medical reasons other than death. But records giving the reasons why men changed to lighter work or became unemployed were nonexistent and information about those who drew sickness benefit was scanty and hard to come by. Therefore, it was decided to restrict the enquiry to the frequency and causes of death. As there were no specific regulations concerning the handling of asbestos in Northern Ireland up to the time of the enquiry, there were no official records of the numbers of men employed. Because of this lack of official recognition, few patients were referred to the pneumoconiosis panels and no special arrangements were in existence for recording the causes of death in this group. The enquiry was conducted in three stages - the identification of the population at risk, the identification of the men who had died and, finally, the analysis of the information which could be obtained about these deaths.

To define the population at risk, a preliminary investigation of the employers' and trades union records was made. Work on the other two studies had indicated that these records were not complete and became progressively less so the further back they were traced. But other work on the malignant hazards of asbestos exposure indicated a long latent period (Knox, Doll, and Hill, 1965; Elmes, 1966), so that positive results could be expected only if a 
working population could be studied over a long period. A compromise was achieved by choosing 1940 as the starting point, and this is a study of the fate of all men known to have been employed on insulation work in that year, irrespective of age and previous experience.

\section{Methods}

\section{The population}

A list of all the men employed as insulators and pipe coverers during 1940 was drawn up. The sources of information were the trade union membership lists for this particular trade (11/72 Insulation Branch of the Transport and General Workers' Union) and the books and card indexes of the various employers. These records were incomplete but were supplemented with information obtained by interviewing other insulators. An intensive study of this population over the last five years makes it extremely unlikely that the final list falls as much as $5 \%$ short of the actual total particularly as this trade was confined to men from a relatively small number of families who lived close to the shipyard in Belfast.

Follow-up was not easy because the original addresses were often useless because of war damage and slum clearance, but family relationships often helped in tracing those still living. All those still alive were interviewed. Arrangements were made with the general practitioners and other doctors concerned with the care of the living men to keep us informed about their health. Deaths occurring after the beginning of the enquiry were reported to the coroner and necropsy was carried out wherever possible. When deaths had already occurred, information was obtained from the nearest available relative as to the date and place of death and previous illnesses involving hospital admission or investigation. This was followed up with the co-operation of the Registrar General who confirmed the place and date and gave the registered cause of death. Records of the hospitals, Queen's University Department of Pathology, and the Forensic Pathology Department were then searched for additional information. Hospital records, $x$-rays, pathological reports, and, where it was available, the actual histological material were re-examined in order to determine the cause of death in the light of current diagnostic criteria.

Both for the living and for the dead as much information as was available was recorded about each man (his occupational history, medical history, abode, and smoking habits). A family history was also taken to make sure that no relatives who were insulation workers had been missed.

\section{Methods of analysis}

Evidence of occupational effect on mortality was sought by comparisons within the group and by comparing the group with the male population of Northern Ireland as a whole.

It was not thought to be possible, with the resources available, to select and investigate a control group of the working population and follow its mortality in the same way.

Comparisons within the group The men were divided into groups according to the age at which they became insulators and this was taken to be their first significant exposure to asbestos. On examining the material it was found that very few of the men employed in 1940 left after a short period of employment. The majority continued working until they became disabled and died, or until they retired.Therefore, those whojoined the industry young had the longest exposure and those who joined late the shortest exposure. The distribution of men according to age in 1940 and age at entry into the industry is shown in Table 1. Age survival curves were constructed for each of the four groups of men who joined up to the age of 20 (inclusive), 21 to 30,31 to 40 , and over 40 years (Fig. 1 and Table 2). Age survival curves dividing the men into groups according to their duration of exposure were also constructed but showed similar results. In the construction of these curves it is the proportion of each group at risk surviving each five-year age period that is plotted.

TABLE 1

Distribution of Men according to Age in 1940 ANd Age At ENTry

\begin{tabular}{|c|c|c|c|c|c|}
\hline \multirow{2}{*}{$\begin{array}{c}\text { Age in } \\
1940\end{array}$} & \multicolumn{4}{|c|}{ Age at entry } & \multirow{2}{*}{ Total } \\
\hline & Up to 20 & $21-30$ & $31-40$ & $41+$ & \\
\hline $\begin{array}{c}\text { Up to } 19 \\
20-24 \\
25-29 \\
30-34 \\
35-39 \\
40-44 \\
45-49 \\
50-54 \\
55-59 \\
60 \text { and over }\end{array}$ & $\begin{array}{r}4 \\
13 \\
8 \\
4 \\
8 \\
15 \\
3 \\
3\end{array}$ & $\begin{array}{r}3 \\
10 \\
16 \\
9 \\
8 \\
4 \\
5\end{array}$ & $\begin{array}{r}3 \\
15 \\
10 \\
4 \\
3 \\
1\end{array}$ & $\begin{array}{l}3 \\
4 \\
4 \\
2 \\
3\end{array}$ & $\begin{array}{r}4 \\
16 \\
18 \\
23 \\
32 \\
36 \\
15 \\
15 \\
3 \\
3\end{array}$ \\
\hline Total & 58 & 55 & 36 & 16 & 165 \\
\hline
\end{tabular}

Comparison with the general population The Northern Ireland Registrar General kindly provided tables of male deaths for the whole province for each year from 1940 onwards. The deaths were listed in five-year age groups with an estimate of the total population for this age group for the relevant year based on the census. The tables gave figures for cancers of the lung, mediastinum, and pleura (Nos. 162-4) and for cancer of all types as well as for deaths due to all causes.

The insulators were divided into the same five-year age groups for each year of the study to give the "population at risk', and the number of deaths in each group observed in each year was recorded as the 'observed deaths'. For the purpose of the analysis both the Registrar General's figures and the figures for the insulators were aggregated into five-year periods (Table 3). The figure for 'expected' deaths for each five-year period was obtained by calculating the expected deaths for each individual year and then adding the five years together. In testing the significance 
(a)

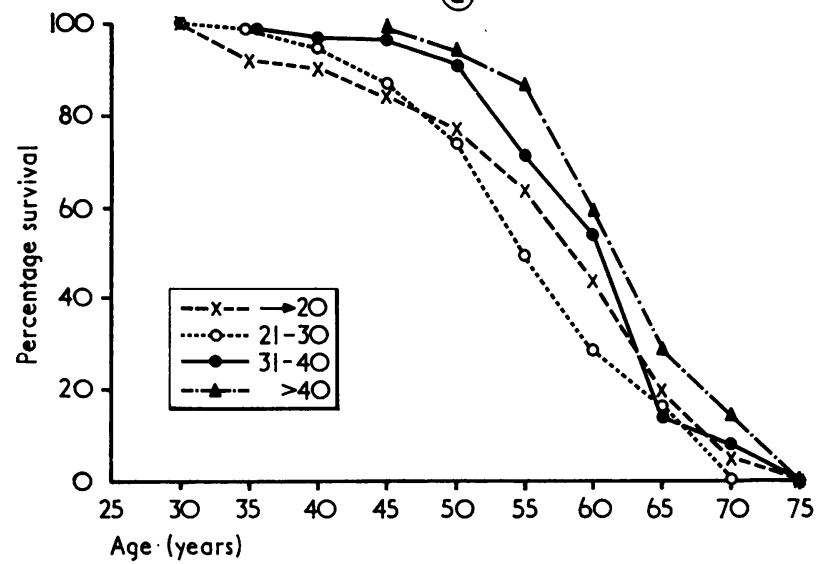

(b)

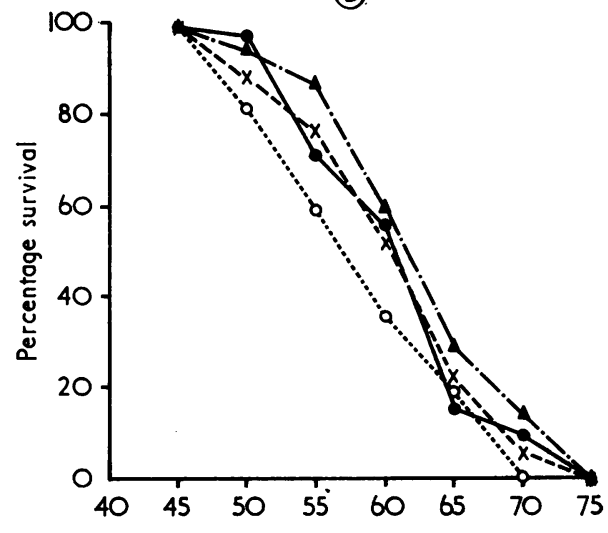

FIG. 1. Influence of age at entry into insulation work on survival at different ages: $(a)$ all deaths in the younger entry groups are included; (b) deaths occurring in the younger entry groups before the age of $\mathbf{4 5}$ are excluded so that all groups start at $100 \%$ at the age of 45 and their survival from then is more directly comparable. Each point on each curve represents the percentage of those at risk surviving to that age.

of differences between observed and expected numbers of deaths $\chi^{2}$ was calculated directly from this difference and the expected values.

Although this method makes due allowance for age and sex and for the changing pattern for mortality in the province during the last 25 years, no allowance is possible for more precise domicile, for social class or for smoking habits. Where figures for the county Borough of Belfast were available these are shown in the tables. But only fragmentary information about the effect of social class (Park, 1965-6) and cigarette smoking (Wicken, 1966) on the pattern of mortality was available. This information was used to test the validity of the conclusions drawn from the comparison with the general population.

TABLE 2

Deaths ANd Age at Entry

\begin{tabular}{|c|c|c|c|c|c|c|}
\hline \multirow{2}{*}{ Age at entry } & \multicolumn{6}{|c|}{ Age period } \\
\hline & Up to 45 & $46-50$ & $51-55$ & $56-60$ & $61-65$ & $66-69$ \\
\hline $\begin{array}{l}\text { Up to } 20 \text { (mean } 16.9) \\
\text { At risk } \\
\text { Died } \\
\text { Rate (\% per year) }\end{array}$ & $\begin{array}{c}54 \\
7 \\
0.46\end{array}$ & $\begin{array}{c}41 \\
5 \\
2 \cdot 5\end{array}$ & $\begin{array}{c}31 \\
3 \\
1 \cdot 9\end{array}$ & $\begin{array}{c}25 \\
7 \\
5 \cdot 6\end{array}$ & $\begin{array}{r}14 \\
7 \\
10\end{array}$ & $\begin{array}{c}3 \\
2 \\
13 \cdot 3\end{array}$ \\
\hline $\begin{array}{l}21-30 \text { (mean } 25 \cdot 0) \\
\text { At risk } \\
\text { Died } \\
\text { Rate (\% per year) }\end{array}$ & $\begin{array}{r}53 \\
7 \\
0.6\end{array}$ & $\begin{array}{c}43 \\
7 \\
3 \cdot 2\end{array}$ & $\begin{array}{c}27 \\
6 \\
4 \cdot 5\end{array}$ & $\begin{array}{c}16 \\
5 \\
6 \cdot 2\end{array}$ & $\begin{array}{r}10 \\
4 \\
8\end{array}$ & $\begin{array}{r}2 \\
2 \\
20\end{array}$ \\
\hline $\begin{array}{l}\text { 31-40 (mean } 35 \cdot 5) \\
\text { At risk } \\
\text { Died } \\
\text { Rate (\% per year) }\end{array}$ & $\begin{array}{r}36 \\
1 \\
0 \cdot 3\end{array}$ & $\begin{array}{c}35 \\
2 \\
1 \cdot 1\end{array}$ & $\begin{array}{c}33 \\
7 \\
4 \cdot 2\end{array}$ & $\begin{array}{c}24 \\
7 \\
5 \cdot 8\end{array}$ & $\begin{array}{r}10 \\
6 \\
12\end{array}$ & $\begin{array}{l}2 \\
0 \\
0\end{array}$ \\
\hline $\begin{array}{l}\text { Over } 40 \text { (mean } 45.5) \\
\text { At risk } \\
\text { Died } \\
\text { Rate (\% per year) }\end{array}$ & 二 & $\begin{array}{c}15 \\
1 \\
1 \cdot 3\end{array}$ & $\begin{array}{c}14 \\
1 \\
1 \cdot 4\end{array}$ & $\begin{array}{c}13 \\
4 \\
6 \cdot 2\end{array}$ & $\begin{array}{r}8 \\
4 \\
10\end{array}$ & $\begin{array}{r}4 \\
2 \\
10\end{array}$ \\
\hline
\end{tabular}

'At risk' = number of men in relevant 'age at entry' group surviving to the beginning of the age period who could have lived to the end of the age period by the time the study was made. 
TABLE 3

Part of Table to show Method of calculating EXPECTED DEATHS

\begin{tabular}{|c|c|c|c|}
\hline Age group & $1945-9$ & $\begin{array}{l}\text { Year } \\
1950-4\end{array}$ & $1955-9$ \\
\hline \multicolumn{4}{|l|}{$20-24$} \\
\hline $25-29$ & $\begin{array}{l}\text { (1) } 57000 \\
\text { (2) } 112 \\
\text { (3) } 15 \\
\text { (4) } 0 \cdot 155 \\
\text { (5) } 1\end{array}$ & & \\
\hline $30-34$ & $\begin{array}{l}\text { (1) } 47500 \\
\text { (2) } 123 \\
\text { (3) } 18 \\
\text { (4) } 0 \cdot 256 \\
\text { (5) } 1\end{array}$ & $\begin{array}{l}\text { (1) } 47700 \\
\text { (2) } 102 \\
\text { (3) } 14 \\
\text { (4) } 0 \cdot 136 \\
\text { (5) } 1\end{array}$ & \\
\hline $35-39$ & & $\begin{array}{l}\text { (1) } 45000 \\
\text { (2) } 138 \\
\text { (3) } 17 \\
\text { (4) } 0 \cdot 23 \\
\text { (5) } 1\end{array}$ & $\begin{array}{l}\text { (1) } 40600 \\
\text { (2) } 101 \\
\text { (3) } 13 \\
\text { (4) } 0 \cdot 146 \\
\text { (5) } 0\end{array}$ \\
\hline $40-44$ & & & $\begin{array}{l}\text { (1) } 44500 \\
\text { (2) } 169 \\
\text { (3) } 16 \\
\text { (4) } 0 \cdot 285 \\
\text { (5) } 2\end{array}$ \\
\hline
\end{tabular}

(1) Estimated population in Northern Ireland of men in this age group in one of the five years concerned

(2) Deaths due to all causes among men in Northern Ireland in this age group for the same year

(3) Number of insulation workers in this age group at the beginning of the five-year period

(4) Estimated number of deaths due to all causes which should have occurred during the five years. This is calculated by adding $\frac{(2) \times(3)}{(1)}$ for each of the individual years

(5) Observed deaths due to all causes in this group of insulation workers in the five years

Each five-year age group of men in 1940 forms a cohort whose fate can be followed over the years by moving diagonally down the table to the right (see arrows). The number of men surviving the group's five-year experience enters the square diagonally down to the right.

The totals of the vertical columns give the observed and expected deaths for the whole group for each five-year period (see Table 4), and the horizontal totals give the observed and expected deaths in each five-year age group (Table 5).

\section{Results}

\section{Population}

One hundred and seventy men were identified as being employed as insulators or pipe coverers in Northern Ireland in 1940. Five were untraced, leaving 165 for analysis. The distribution by age at entry and age in 1940 is shown in Table 1. From this it is seen that there was a wide scatter of both age and previous exposure at the time when the study started.
About one-third of the men joined the industry before they were 21 years of age and another third joined before they were 31 . Although most of the rest joined before they were 41,16 did not join until they were older. There was no evidence that this pattern of widely differing ages at entry had changed over the previous 25 to 30 years.

\section{Deaths}

Between 1940 and 1966 inclusive 98 (59.5\%) of those traced had died. Table 4 shows the distribution of these deaths in time. As the population grew older the mean ages of those dying tended to rise, and the proportion of the survivors who died in each year also rose. As this pattern of changes was what might be expected from following any group of assorted ages over a period of years, the control studies were needed to determine whether the death rate as a whole, the rate of increase in death rate over the years or the sudden increase from $1 \%$ to over $3 \%$ per year after 1950 differ significantly from that expected.

Comparisons within the group The influence of age at entry and consequently the duration of exposure at a given age is shown by the survival curves (Fig. 1) and tabulated figures (Table 2). A cohort of men joining an industry at an early age will contain some sick men by the time they reach the age of 45 or 50 . These sick men are being carried by their mates. But a cohort of men joining at the age of 40 or later will have to be fit enough to do their share of work. Consequently the late entry group, being healthier, will show a low initial mortality compared with earlier entries (Hammond, Selikoff, and Churg, 1965; Newhouse, 1969). Thus, even adjusting for those deaths which occur before the age of 45 , as has been done in Fig. 1b, the slope of the survival curve of the late entry group (over 40 years) shows the expected difference from the others for the next 10 years. There is no consistent difference relating age of entry or duration of exposure between the other three groups. All four groups show a high mortality beyond the age of 55 and, considering the small numbers involved, the rates are remarkably similar. At the time of the study only five men had lived beyond the age of 70 and these had died at 71 (4) and 72 (1).

Comparison with the general population When the deaths occurring in each five-year period are compared with those expected for the general population adjusted for age, the significance of the figures is revealed. Compared with Northern Ireland males (Fig. 2) there is a progressive divergence throughout the period of observation. At no stage is the experience of the insulators, who were all fit enough to work in 1940, better than that of the population as a whole. The divergence increases with time. This 
TABLE 4

DeATHS IN Five-YeAR DERIODS

\begin{tabular}{|c|c|c|c|c|c|c|}
\hline & \multicolumn{6}{|c|}{ Period } \\
\hline & $1940-4$ & $1945-9$ & $1950-4$ & $1955-9$ & $1960-4$ & $1965-6$ \\
\hline $\begin{array}{l}\text { At risk } \\
\text { Deaths }\end{array}$ & $\begin{array}{r}165 \\
10\end{array}$ & $\begin{array}{r}155 \\
7\end{array}$ & $\begin{array}{r}148 \\
26\end{array}$ & $\begin{array}{r}122 \\
20\end{array}$ & $\begin{array}{r}102 \\
29\end{array}$ & $\begin{array}{r}73 \\
6\end{array}$ \\
\hline $\begin{array}{l}\text { Mean age at death (yr) } \\
\% \text { dying/year }\end{array}$ & $\begin{array}{r}50 \cdot 3 \\
1 \cdot 2\end{array}$ & $\begin{array}{r}51 \cdot 4 \\
0.9\end{array}$ & $\begin{array}{r}54 \cdot 8 \\
3 \cdot 5\end{array}$ & $\begin{array}{r}59 \cdot 0 \\
3 \cdot 3\end{array}$ & $\begin{array}{r}59 \cdot 4 \\
5 \cdot 7\end{array}$ & $\overline{4 \cdot 1}$ \\
\hline $\begin{array}{l}\text { Deaths expected (N.I. males) } \\
\text { Significance } \\
\text { SMR }^{1} \\
\text { Deaths expected (Belfast only) }\end{array}$ & $0.1 \stackrel{5.54}{>\underset{180}{P}>0.05}$ & $\begin{array}{c}5 \cdot 41 \\
P>0 \cdot 1 \\
129\end{array}$ & $\begin{array}{c}6.90 \\
P<0.0001 \\
363 \\
7.2\end{array}$ & $\begin{array}{c}7 \cdot 7 \\
P<0.001 \\
274\end{array}$ & $\begin{array}{l}9.0 \\
P<0.0001 \\
333 \\
10.7\end{array}$ & $0.1>\underset{162}{\stackrel{3 \cdot 1}{\mathrm{P}}>0.05}$ \\
\hline
\end{tabular}

1SMR = standardized mortality ratio. Although the numbers are too small to give the precise meaning to this ratio which it has for large populations, it gives an idea of the order of the difference observed.

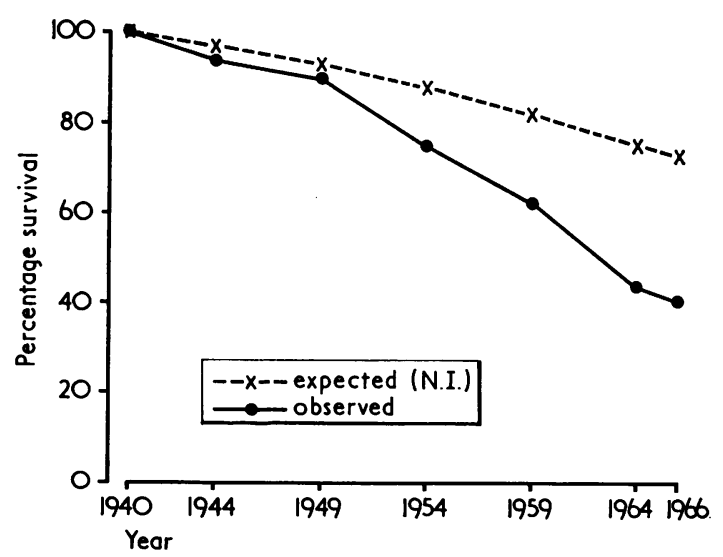

FIG. 2. Survival of insulation workers at 5-year intervals compared with the male population of Northern Ireland adjusted for age. By the end of 1966 only $41 \%$ (67 men) survived compared with $73 \%$ (121 men) expected to survive. information is shown in more detail in Table 4 and a similar comparison by age in Table 5 . To show the order of the difference, standardized mortality ratios (SMRs) are also shown in these tables although the numbers involved are insufficient to give the ratios much precision. The significance of the differences is statistically valid but no allowance is made for the environmental and social factors.

The divergence becomes of obvious significance after 1950, as might be expected from the sudden increase in mortality in the workers at that time. Table 5 shows that the greatest difference between the workers and the general population occurs between the ages of 50 and 59 years.

\section{Causes of death}

Table 6 shows the causes of death observed both as given on the death certificate and as revised in the light of all available information. There were a number of differences in detail between these two lists and there were also a number of cases where the

TABLE 5

Deaths by Age

\begin{tabular}{|c|c|c|c|c|c|c|c|c|}
\hline & \multicolumn{8}{|c|}{ Age } \\
\hline & Up to 39 & $40-44$ & $45-49$ & $50-54$ & $55-59$ & $60-64$ & $65-69$ & $\begin{array}{l}70 \text { and } \\
\text { over }\end{array}$ \\
\hline $\begin{array}{l}\text { At risk } \\
\text { Deaths observed } \\
\text { Deaths expected } \\
\quad \text { (N.I.) } \\
\text { Significance } \\
\text { SMR }\end{array}$ & $\begin{array}{c}153 \\
5 \\
3.2 \\
0.5>P>0.2 \\
156\end{array}$ & $\begin{array}{c}139 \\
8 \\
\\
3.0 \\
0.01>P>0.001 \\
267\end{array}$ & $\begin{array}{c}136 \\
12 \\
\\
4 \cdot 23 \\
P<0 \cdot 001 \\
284\end{array}$ & $\begin{array}{c}111 \\
21 \\
\\
6 \cdot 2 \\
P<0 \cdot 001 \\
329\end{array}$ & $\begin{array}{c}82 \\
23 \\
\\
7 \cdot 0 \\
P<0 \cdot 001 \\
329\end{array}$ & $\begin{array}{c}49 \\
13 \\
\\
6.0 \\
0.01>P>0.001 \\
216\end{array}$ & $\begin{array}{c}18 \\
8 \\
4 \cdot 7 \\
0 \cdot 1>\text { P } 0.05 \\
170\end{array}$ & $\begin{array}{r}8 \\
8 \\
3 \cdot 24 \\
246\end{array}$ \\
\hline
\end{tabular}

${ }^{1}$ See footnote to Table 4. 
TABLE 6

Classification of Causes of Death

\begin{tabular}{|c|c|c|c|}
\hline & $\begin{array}{l}\text { Death } \\
\text { certifi- } \\
\text { cate }\end{array}$ & $\begin{array}{c}\text { Revised } \\
\text { cause }\end{array}$ & $\begin{array}{c}\text { Classification } \\
\text { used in } \\
\text { analysis }\end{array}$ \\
\hline $\begin{array}{l}\text { Malignant } \\
\text { Upper respiratory } \\
\text { Lower respiratory } \\
\text { Pleural mesothelioma } \\
\text { Peritoneal mesothelioma } \\
\text { Gastrointestinal } \\
\text { Genitourinary }\end{array}$ & $\begin{array}{r}1 \\
25 \\
1 \\
0 \\
13 \\
1\end{array}$ & $\left.\begin{array}{r}1 \\
24 \\
4 \\
3 \\
12 \\
1\end{array}\right\}$ & $\begin{array}{r}45 \\
1 \\
28\end{array}$ \\
\hline $\begin{array}{l}\text { Non-malignant } \\
\text { Respiratory } \\
\text { Tuberculosis } \\
\text { Other lung disease } \\
\text { Cardiovascular } \\
\text { Other }\end{array}$ & $\begin{array}{r}6 \\
27 \\
16 \\
8\end{array}$ & $\left.\begin{array}{r}6 \\
26 \\
13 \\
8\end{array}\right\}$ & $\begin{array}{r}53 \\
6 \\
6 \\
26 \\
21\end{array}$ \\
\hline
\end{tabular}

Note: The death certificate diagnosis was revised only when definite evidence was available. There remain among the lower respiratory cancers nine cases which may have been pleural mesotheliomas, and among the gastrointestinal cases two which may have been peritoneal mesotheliomas. The evidence was insufficient in these cases to justify reclassification. The effect of transferring four cases from non-malignant to malignant and increasing the number of lower respiratory and pleural cancer from 26 to 28 on statistical analysis is discussed in the text.

final diagnosis remained in doubt. This affected particularly the diagnosis of mesothelioma; the Registrar General recorded only one pleural case, but three other pleural and three peritoneal cases were diagnosed on the basis of postmortem findings. There were also nine carcinomas of the lung which on review could have been pleural mesotheliomas, and one case classified as a carcinomatosis peritonei which might have been a peritoneal mesothelioma. Because of these difficulties only a much broader classification was used for the statistical analysis. In this classification cancers of the lung and pleura are grouped together and peritoneal mesotheliomas are included in the gastrointestinal group of malignancy. Using this broader classification, the differences between the death certificates and revised diagnoses are less important. The revised diagnoses were used in the comparisons which follow. The effect of raising the number of cancer deaths from 41 to 45 and lower respiratory cancers from 26 to 28 on the statistical significance of any differences observed will be shown to be negligible.

During the first 10 years there were six deaths due to tuberculosis. Evidence of healed disease was found in some later deaths but the disappearance of significant tuberculosis coincides with the availability of satisfactory antituberculosis treatment. The other change in the pattern of causes of death with time (Table 7) is the increase in the proportion of malignant deaths. This increase with time is to be expected in an ageing population and it is necessary to compare this group with the general population to determine its significance.

Malignant disease The comparison between the observed deaths due to cancer of all types and deaths due to the same cause in the populations both of Northern Ireland and of Belfast in particular is shown in Figure 3. There is a marked increase from 1950

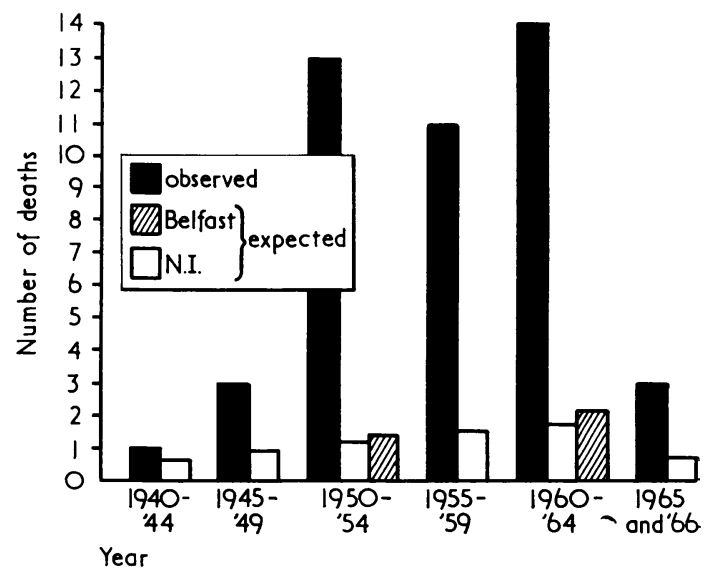

FIG. 3. Deaths due to cancer of all types occurring in insulation workers in each five-year period compared with deaths expected for age-matched males in Northern Ireland as a whole and in the county Borough of Belfast.

TABLE 7

Changes in Causes of Death between 1940 and 1966

\begin{tabular}{l|cccrrrr}
\hline & $1940-4$ & $1945-9$ & $1950-4$ & $1955-9$ & $1960-4$ & $1965-6$ & Total \\
\hline Cancer (all types) & 1 & 2 & 13 & 11 & 15 & 3 & 45 \\
Tuberculosis & 3 & 3 & 0 & 0 & 0 & 0 & 6 \\
Non-tuberculous chronic lung disease & 5 & 1 & 7 & 3 & 7 & 3 & 26 \\
Other causes & 1 & 1 & 6 & 6 & 7 & 0 & 21 \\
\hline$-10-1$ & 10 & 7 & 26 & 20 & 29 & 6 & 98 \\
Total & & & & & & & \\
\hline
\end{tabular}


onwards and from then on cancer deaths are nearly eight times more frequent than expected. The figures are given in Table 8.

Twenty-eight of the 45 deaths were classified as cancers of the larynx, lung or pleura, which represents $75 \%$ of the excess deaths due to malignant disease. The distribution of these deaths by age as compared with Northern Ireland males is shown in Table 9. For the whole group these cancers were 17 times more frequent than expected.

Mesotheliomas Towards the end of the period covered by the survey an intensive search was being made for mesotheliomas in Northern Ireland, but a maximum of 12 new cases was recorded for any year. As these cases were derived from the whole population of Northern Ireland the expected incidence for a group of 165 men is negligible even when considered as a proportion of the $\mathbf{9 8}$ deaths. Therefore all the seven confirmed cases (four pleural and three peritoneal) must be considered in excess of expectation and this incidence is highly significant.

Other cancers There remain 17 deaths due to nonrespiratory malignant disease. For Northern Ireland males the expected figure was $5 \cdot 16$ deaths. The threefold excess is highly significant $\left(\chi^{2}=28.04\right.$; $P<0.005)$. Comparisons with the general population under more precise diagnostic headings were not made because of doubts about the precise diagnosis in many cases. But 15 (including three peritoneal mesotheliomas) were classified as gastrointestinal in origin. The revised diagnoses in these cases were three mesotheliomas, four carcinomas of the stomach, four of the colon, two of the rectum, one of the head of pancreas, and one lymphosarcoma of the small intestine. Of these, one classified as gastric and one as rectal carcinoma could have been mesotheliomas.

Non-malignant disease There were 53 deaths due to non-malignant disease when only 30.9 were expected. This difference is highly significant $\left(\chi^{2}=18 \cdot 1\right.$; $P<0.005)$. The mortality was higher than expected throughout the period of observation; the sharp rise from 1950 onwards noted for malignant disease was not seen. The 13 cardiovascular and eight other nonrespiratory deaths were rather fewer than expected. and the excess lies among those $\mathbf{2 6}$ cases classified as lung disease other than tuberculosis. It is difficult to put these into precise diagnostic categories so as to compare them with the expected death rates for the

TABLE 8

Deaths due to All Types of Cancer in Five-year Periods

\begin{tabular}{l|ccccccc}
\hline & $1940-4$ & $1945-9$ & $1950-4$ & $1955-9$ & $1960-4$ & $1965-6$ & Total \\
\hline At risk & 165 & 155 & 148 & 122 & 102 & 73 & 165 \\
Deaths & 1 & 3 & 13 & 11 & 14 & 3 & $45^{2}$ \\
Expected Northern Ireland males & 0.605 & 0.913 & $1 \cdot 275$ & $1 \cdot 529$ & $1 \cdot 747$ & $0 \cdot 774$ & $6 \cdot 8$ \\
SMR & 165 & 333 & 1020 & 720 & 800 & 390 & 670 \\
Belfast only & - & - & $1 \cdot 466$ & - & $2 \cdot 243$ & - & - \\
\hline
\end{tabular}

For the whole group $\chi^{2}=234 ; P<0.0005$

${ }^{1}$ See footnote to Table 4 .

241 registered deaths due to all types of cancer.

TABLE 9

Deaths due to Cancer of the Larynx, Lung, and Pleura by Age

\begin{tabular}{l|cccccccc}
\hline & \multicolumn{10}{c}{ Age } \\
\cline { 2 - 9 } & Up to 44 & $45-49$ & $50-54$ & $55-59$ & $60-64$ & $65-69$ & $70+$ & Total \\
\hline At risk & 139 & 136 & 111 & 82 & 49 & 18 & 8 & 165 \\
Observed deaths & 1 & 2 & 3 & 4 & 7 & 6 & 5 & $28^{2}$ \\
Expected (N.I.) & 0.006 & $0 \cdot 141$ & $0 \cdot 295$ & $0 \cdot 492$ & $0 \cdot 380$ & $0 \cdot 222$ & $0 \cdot 103$ & $1 \cdot 639$ \\
SMR $^{1}$ & - & 1400 & 990 & 810 & 1840 & 2830 & 4850 & 1760 \\
\hline
\end{tabular}

For the whole group even if three deaths were expected $\chi^{2}=212 ; \mathrm{P}<0.0005$.

1See footnote to Table 4 .

${ }^{2} 26$ registered deaths due to these cancers. 
population as a whole. Asbestosis was mentioned on the death certificate and regarded as a contributory cause of death in nine cases, one being a case of tuberculosis. There were 11 other cases with radiological evidence of fibrosis but no histological information. In eight cases there was no evidence whether asbestosis or other fibrosis was present or not. So that although there is strong presumptive evidence that pulmonary fibrosis due to asbestosis contributed to the excessive mortality among this group of men, its numerical importance cannot be assessed.

Pulmonary fibrosis and malignant disease In 40 of the deaths there was radiological or postmortem evidence of extensive fibrosis (excluding tuberculosis) easily sufficient to have justified their certification as cases of asbestosis. Twenty-two $(55 \%)$ of these patients died of cancer; $16(40 \%)$ of lung, five gastrointestinal, and one of larynx. There were no cases of pleural or peritoneal mesothelioma. Conversely, of those 24 cases finally classified as carcinoma of the lung, there was no information about five, and extensive fibrosis in 11 . The remaining eight all showed some fibrosis on $x$-ray or histological examination. There were no cases of carcinoma of the bronchus known to have no lung fibrosis. Of the seven mesotheliomas, one pleural case showed no lung fibrosis at all, the other pleural and three peritoneal cases showed minimal fibrosis on histological examination only, and none showed radiological evidence of fibrosis.

\section{Influence of other environmental factors}

The primary analysis of the deaths among this small group of men is based on a comparison with the whole male population of Northern Ireland. However, these men lived and worked in a densely populated area of Belfast and belonged to the skilled and semiskilled social class. On the grounds of both domicile and social class their mortality and particularly their mortality from lung cancer might be expected to be above that of the population of Northern Ireland as a whole. The third factor is the possibility that this group of men smoked more cigarettes than other men in Northern Ireland. Taking each of these environmental factors in turn and considering also the effect of reclassifying the causes of death, their importance can be estimated as follows:

Domicile The total deaths expected for Belfast males for 1950-4 and 1960-4 shown in Table 4 are not sufficiently different from Northern Ireland as a whole to alter the significance of the differences observed. No figures were available in the Registrar General's tables for cancer of the lung in Belfast males, but Wicken (1966) analysed the data available for 1960-2. He gives a figure of 197 deaths due to lung cancer per 100000 living for men over the age of 35 years living in 'Inner Belfast' compared with 100 per Northern Ireland as a whole. (Inner Belfast produced 258 of the 873 lung cancer deaths analysed.) This would bring the expected figure for cancer of the lung in insulation workers from 1.64 to 3.23 where 28 were observed (Table 9). The difference remains highly significant $\left(\chi^{2}=193 ; P<0.0005\right)$ and would not be less significant if the death certificate figure of 26 observed cases were used.

Social class Insulation workers are a mixed group of semiskilled and skilled workers and if it is assumed that they represent a group, half of whom are skilled and half semiskilled, then allowance can be made for social class based on the data for Northern Ireland given by Park (1965-6) and Wicken (1966), both based on the 1961 census. Their figures for class III and IV manual workers give an average SMR of 97.5 for all deaths, 100 for all cancers, and 114 for cancers of the lung. Therefore adjustment of the expected figures for social class alone would not affect the significance of the differences observed in insulation workers.

Smoking habits There were 46 men in the group whose smoking habits were not known, and of the remainder only five did not smoke. Comparisons within the group (see Table 10) showed that neither of the two deaths in non-smokers was due to cancer. There was no significant difference between the death rates observed due to respiratory cancer between those who smoked more and those who smoked less than 20 cigarettes per day.

Taking those whose smoking habits were known and comparing them with the people surveyed by Wicken (1966) in Inner Belfast (Table 11), it is evident that the insulators were heavy smokers. These figures indicate that the expected frequency of lung cancer for the insulators should be $\mathbf{1 \cdot 2 6}$ times that for Inner Belfast.

These three factors are interrelated in that the population of Inner Belfast contains a higher proportion of social classes IV, V, and VI than Northern Ireland as a whole and that these social classes also smoke more. Therefore to make an estimate of the combined effects of the three factors by regarding them as independent tends to exaggerate the result. The figures given in Table 12 are as near an approximation as is possible with the information available but must still be an overestimate of the combined effect. The numbers of deaths expected are increased by factors of $1.08,1.22$, and 2.83 for all deaths, all cancers and respiratory cancers, but in spite of this the differences between observed and expected would remain highly significant even if the death certificate figures of 41 due to all cancers and 26 due to lower respiratory cancer had been used. 
TABLE 10

SMOKING HaBits AND MoRTality

\begin{tabular}{|c|c|c|c|c|c|}
\hline & \multirow{2}{*}{ At risk } & \multirow{2}{*}{$\begin{array}{c}\text { Deaths } \\
\text { (all causes) }\end{array}$} & \multicolumn{3}{|c|}{ Deaths (resp. cancer) } \\
\hline & & & Observed & Expected & $O / E$ \\
\hline $\begin{array}{l}\text { Non-smokers } \\
\text { Less than } 20 / \text { day with pipe and ex-smokers } \\
\text { More than 20/day } \\
\text { Not known }\end{array}$ & $\begin{array}{r}5 \\
62 \\
52 \\
46\end{array}$ & $\begin{array}{r}2 \\
38 \\
29 \\
29\end{array}$ & $\begin{array}{r}0 \\
10 \\
9 \\
9\end{array}$ & $\begin{array}{l}-\overline{0.67} \\
0.53 \\
0.462\end{array}$ & $\begin{array}{c}\overline{14} \\
17 \\
19 \cdot 5\end{array}$ \\
\hline
\end{tabular}

Note: There is no significant difference between the frequency of cancer of the lung or death due to all causes in the two smoking groups $(0.6>P>0.5$ in both cases).

TABLE 11

KNOWN SMOKING Habits COMPARED WITH 'INNER Belfast' MALES

\begin{tabular}{l|cc|c}
\hline \multirow{2}{*}{ Cigarettes/day } & \multicolumn{2}{|c|}{ Inner Belfast } & \multirow{2}{*}{$\begin{array}{l}\text { \% Insulators } \\
\text { (actual nos.) }\end{array}$} \\
\cline { 2 - 3 } & $\begin{array}{c}\text { Males } \\
35+y r\end{array}$ & $\begin{array}{c}\text { SMR } \\
\text { (lung cancer) }\end{array}$ & \\
\hline None & $15 \%$ & 18 & $4.2 \%(5)$ \\
$1-10$ & $22 \%$ & 74 & $22.7 \%(27)$ \\
$11-22$ & $31 \%$ & 123 & $50 \cdot 5 \%(60)$ \\
$23+$ & $16 \%$ & 302 & $23.0 \%(25)$ \\
Other (pipe, etc) & $17 \%$ & 81 & $1.8 \%(2)$ \\
\hline
\end{tabular}

TABLE 12

Significance of Excess Mortality AdJusted for Social Class, Domicile, and Smoking

\begin{tabular}{l|c|c|c}
\hline & $\begin{array}{c}\text { All } \\
\text { causes }\end{array}$ & $\begin{array}{c}\text { All } \\
\text { cancers }\end{array}$ & $\begin{array}{c}\text { Respiratory } \\
\text { cancer }\end{array}$ \\
\hline Basic prediction & & & \\
(N. Ireland males) & 37.6 & 6.84 & 1.64 \\
Adjustment factor & 1.08 & 1.22 & $2 \cdot 83$ \\
Adjusted prediction & 40.6 & 8.35 & 4.64 \\
Observed & 98 & $45^{2}$ & $28^{2}$ \\
$\chi^{2}$ & 107.3 & 167.9 & 121.0 \\
$\mathbf{P}$ & $<0.0005$ & $<0.0005$ & $<0.0005$ \\
\hline
\end{tabular}

${ }^{1}$ Adjustment factor is produced by multiplying together the individual factors $\left(\frac{\mathrm{SMR}}{100}\right)$ for social class, domicile, and smoking. In the case of smoking, only the difference in smoking habits between men domiciled in Inner Belfast and the insulation workers was taken into consideration.

${ }^{2}$ If the figures 41 and 26 are substituted for the 45 and 28 shown for all cancers and respiratory cancer the corresponding figures for $\chi^{2}$ are 135 and 101 and $P<0.0005$ in both cases.

\section{Duration of the risk}

Although the higher mortality in insulators appears to have been present throughout the whole period, it became significantly different from the rest of the population from 1950 onwards. If the exposure to asbestos dust took a finite time (say 25 years) to produce death, then the increase in deaths from 1950 onwards might have been due to a deterioration in working conditions in about 1925. In Fig. 4 the deaths are plotted at five-year intervals, comparing the experience of those who started before 1920 with those who started between 1920 and 1930 and those who started after 1930 . If there was a marked change in conditions of work in the period before 1940, then there would be a synchronous change in all three curves. Figure 4 shows that there was a progressive increase in mortality in all three groups as the time

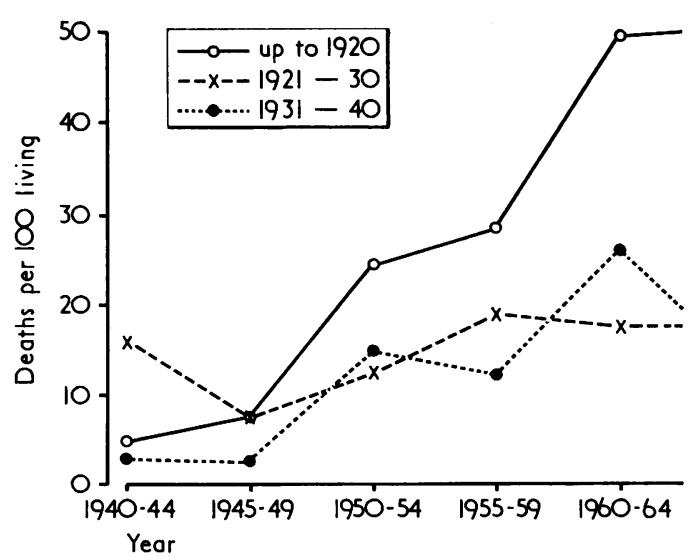

FIG. 4. Comparison of number of deaths due to all causes per 100 living insulation workers occurring in each five-year period for those men who started work up to 1920, 1921-30, and 1931-40. 
passed, the increase being steepest in those who had been in the industry longest and who were therefore older. There is no evidence of a synchronous change in the direction of the curves compatible with a marked change in working conditions.

\section{Discussion}

The follow-up of 165 men out of a group of 170 from 1940 to 1966 has shown a high premature mortality compared with the population of Northern Ireland. This mortality is so far in excess of expectation that it cannot be accounted for by other known factors such as smoking, domicile or social class. The excess of deaths is thought to be due to some factor related to their work. Similar mortality has been described by Hammond et al. (1965) in insulation workers in New York where a smaller proportion of the work is related to ships. The pattern also resembles that shown in workers employed in asbestos factories before the introduction of protective measures and who have survived into the present era (Knox et al., 1965; Newhouse, 1969). The excessive mortality appears to be due to the inhalation of asbestos dust. There is no quantitative information about the amount of dust exposure these insulation workers received other than by inference from the severity of their occupational disease. They are known to have been exposed to three of the main commercial types, namely, chrysotile, amosite, and crocidolite. They are unlikely to have had much exposure to anthophyllite.

The complete pattern of deaths in these insulation workers will not be revealed until they have all died. This study shows that the excess of deaths was already occurring at the beginning of the period under study and had reached statistically significant proportions after only 15 years. An excess of deaths due to chronic non-tuberculous lung disease was occurring throughout the period. In at least eight of these cases asbestosis appears to have been a contributory cause of death and lung fibrosis due to this cause may have contributed in at least 11 more of the 26 deaths in this category. This incidence of fatal lung fibrosis is lower than that encountered in certain factory groups before precautions were taken but higher than that predicted for workers employed in factories only after precautions were taken (Knox et al., 1965; Smither, 1965).

Numerically more important as a cause of premature death was malignant disease. The deaths due to cancer of all types first exceeded expectation significantly in the period 1950-4 and altogether about 38 deaths in excess of expectation occurred. There appears to be no particular reason why these deaths began to exceed expectation at this time other than the fact that the men were reaching the susceptible age in increasing numbers.

As might be expected from the high incidence of lung fibrosis (Buchanan, 1965), the commonest malignant cause of death was lung cancer. The precise numbers cannot be given because of difficulties in retrospective diagnosis. There were 28 cases classified as cancers of the larynx, lung or pleura of whom four were probably mesotheliomas. The excess of respiratory neoplasms began to appear in men over the age of 45 and increased in frequency with age. Making every possible allowance for other factors the mortality was 28 (or 26 if the registered cause of death is used) instead of the predicted 4.64, i.e., nearly $6\left(5 \frac{1}{2}\right)$ times that expected (Table 12$)$. The findings suggest that men developing fibrosis are more likely to die with primary bronchial cancer whereas mesotheliomas may occur with minimal or no evidence of asbestosis. There were too few nonsmokers to confirm the suggestion that lung cancer seldom, if ever, occurs in non-smokers (Selikoff, Churg, Hammond, and Kaffenburgh, 1968).

Mesotheliomas appear as a relatively frequent fatal tumour. Although only one case was recorded on the death certificate, three other pleural and three peritoneal cases were diagnosed in retrospect and there may have been others among those in whom the information was insufficient. This is similar to the experience of Newhouse and Wagner (1969). Although the proportion of bronchial carcinoma to pleural mesothelioma may be similar to the London study, the proportion of peritoneal mesotheliomas is lower. Ascertainment of peritoneal mesotheliomas is even lower in the general population in Belfast (Elmes and Wade, 1965).

Cancer of the lung and mesotheliomas do not account for all the excess of deaths; a significant excess of other cancers remain, as was found by Newhouse (1969), and most of these appear to be in the gastrointestinal tract (Hammond et al., 1965).

As the men grow older the pattern of causes of death changes. In the final analysis there may be a larger proportion of deaths due to 'other causes', particularly to cardiovascular disease. The excess deaths due to fibrotic lung lesions and to cancers of the lung and gastrointestinal tract may be less frequent and mesotheliomas (partly because of necropsy and therefore more precise diagnosis) may appear more frequent. It will be of interest to see how many of this group of men live beyond the age of 70 .

The Merewether and Price report was issued in 1930 and the regulations for factory asbestos workers came into force in 1933. If the insulation workers had been followed prospectively even from 1940 their hazard would have been recognized by 1955 .

This investigation was made possible by the provision of funds from the British Empire Cancer Campaign and by the willing help of the workers themselves, their employers, their union, the staff of the Registrar General (NI), and innumerable doctors and hospital records personnel. 
Statistical advice was given by the Department of Medical Statistics of Queen's University, Belfast.

\section{References}

Buchanan, W. D. (1965). Asbestosis and primary intrathoracic neoplasms. Ann. N.Y. Acad. Sci., 132, 507-518.

Elmes, P. C. (1966). The epidemiology and clinical features of asbestosis and related diseases. Postgrad. med. J., 42, 623-635.

- and Wade, O. L. (1965). Relationship between exposure to asbestos and pleural malignancy in Belfast. Ann. N.Y. Acad. Sci., 132, 549-557.

Hammond, E. C., Selikoff, I. J., and Churg, J. (1965). Neoplasia among insulation workers in the United States with special reference to intra-abdominal neoplasia. Ann. N.Y. Acad. Sci., 132, 519-525.

Knox, J. F., Doll, R. S., and Hill, I. D. (1965). Cohort analysis of changes in incidence of bronchial carcinoma in a textile asbestos factory. Ann. N.Y. Acad. Sci., 132, 526-535.

Langlands, Jean H. M., Wallace, W. F. M., and Simpson, Marion J. C. (1971). Insulation Workers in Belfast. 2. Morbidity in men still at work. Brit. J. industr. Med., 28, 217-225.
Merewether, E. R. A., and Price, C. W. (1930). Report on Effects of Asbestos Dust on the Lungs and Dust supression in the Asbestos Industry. H.M.S.O., London.

Newhouse, M. L. (1969). A study of the mortality of workers in an asbestos factory. Brit. J. industr. Med., 26, 294-301. -, and Wagner, J. C. (1969). Validation of death certificates in asbestos workers. Brit. J. industr. Med., 26, 302-307.

Park, A. T. (1965-6). Occupational mortality in N. Ireland (1960-2). J. Statist. and Social Enquiry Society of Ireland, 21, Pt. IV, 24-42.

Selikoff, I. J., Churg, J., Hammond, E. C., and Kaffenburgh, J. (1968). Prospective studies of asbestos neoplasia in asbestos workers. Paper 72 Proc. 2nd int. Conf. Biological Effects of Asbestos, Dresden. To be published.

Smither, W. J. (1965). Secular changes in asbestosis in an asbestos factory. Ann. N.Y. Acad. Sci., 132, 166-181.

Wallace, W. F. M., and Langlands, Jean H. M. (1971). Insulation workers in Belfast. 1. Comparison of a random sample with a control population. Brit. J. industr. Med., 28, $211-216$.

Wicken, A. J. (1966). Environmental and Personal Factors in Lung Cancer and Bronchitis Mortality in Northern Ireland 1960-62. Tobacco Research Council Research Paper No. 9. London.

Received for publication July 21, 1970. 